\title{
ANÁLISE FOTÔNICA E ULTRA-ESTRUTURAL DA EPIDERME FOLIAR DE Galinsoga parviflora CAV. E G. ciliata (RAF.) BLAKE, ASTERACEAE
}

\section{OPTICAL AND ULTRASTRUCTURAL ANALYSIS OF THE LEAF EPIDERMIS OF Galinsoga parviflora CAV. AND G. ciliata (RAF.) BLAKE, ASTERACEAE}

\section{DUARTE, M. do R. ${ }^{1 *}$; LOPES, J. F. ${ }^{2}$}

\author{
Professora do Departamento de Farmácia, Universidade Federal do Paraná (UFPR) \\ ${ }^{2}$ Graduando do Curso de Farmácia, UFPR \\ * Autor para correspondência: Rua Pref. Lothário Meissner, 3400, 80210-170, Curitiba, PR, marciard@ufpr.br
}

Recebido em: 12/2003

Aprovado em: 01/2004

RESUMO

Galinsoga parviflora Cav. e G. ciliata (Raf.) Blake são herbáceas medicinais, empregadas popularmente no tratamento de ulcerações cutâneas e distúrbios hepáticos. Este trabalho teve por objetivo caracterizar a epiderme foliar dessas espécies, por meio de análise fotônica e ultra-estrutural. Folhas adultas foram fixadas e submetidas a técnicas usuais de microscopia fotônica e de varredura. Ambas as espécies apresentam epiderme foliar uniestratificada e revestida por cutícula delgada e levemente estriada. Em vista frontal, as células epidérmicas revelam contorno sinuoso e estômatos anomocíticos ocorrem em ambas as superfícies. Tricomas tectores pluricelulares e unisseriados predominam na face adaxial. Esse anexo epidérmico é comparativamente mais numeroso em G. ciliata.

Palavras-chave: picão-branco, planta medicinal, farmacognosia, morfo-anatomia.

ABSTRACT

Galinsoga parviflora Cav. and G. ciliata (Raf.) Blake are medicinal herbs, popularly employed for treating cutaneous ulcers and hepatic insufficiency. This work has aimed to characterize the leaf epidermis of these species, by means of optical and ultrastructural analysis. Mature leaves were fixed and undergone usual optical and scanning microtechniques. Both species have got uniseriate leaf epidermis, coated by thin and slightly striated cuticle. In face view, the epidermal cells show sinuous contour and anomocytic stomata are seen on both surfaces. Pluricellular and uniseriate non-glandular trichomes predominate on the upper side. This epidermal appendage is comparatively more frequent in $\mathrm{G}$. ciliata.

Key words: shaggy soldier, medicinal plant, pharmacognosy, morpho-anatomy.

\section{INTRODUÇÃO}

Galinsoga parviflora Cav. e G. ciliata (Raf.) Blake (Fig. 1, 2) são herbáceas ruderais, anuais, medindo cerca de $40 \mathrm{~cm}$ de altura (WARWICK, SWEET, 1983; BRANDÃO et al., 1991; JHA, SAH, CHETTRI, 1992; ALICE et al., 1995), e denominadas comumente de picão-branco, botão-de-ouro e fazendeiro (VIDAL, VIDAL, 1965; MACEDO et al., 1991; LORENZI, 2002). Levantamentos etnobotânicos revelam que a população emprega essas espécies na medicina tradicional, para o tratamento de ulcerações de pele e distúrbios hepáticos e broncopulmonares (ALICE et al., 1991; LORENZI, 2002), como antiinflamatório (ALICE et al., 1995) e na alimentação (WEHMEYER, ROSE, 1983).

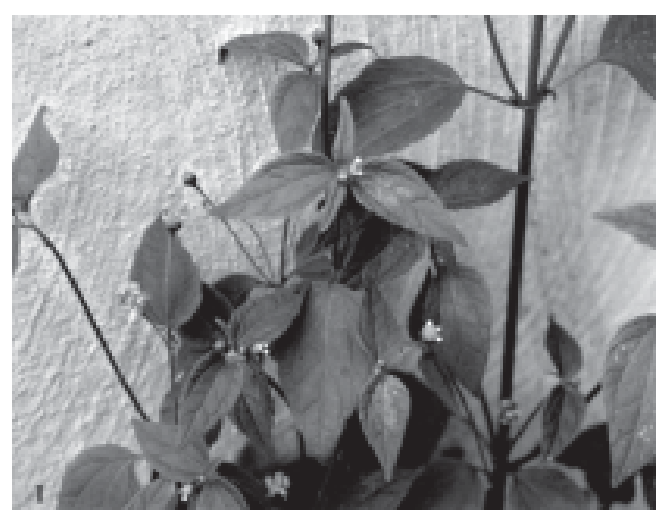

FIGURA 1 - Galinsoga parviflora CAV., Asteraceae: Aspecto Geral 


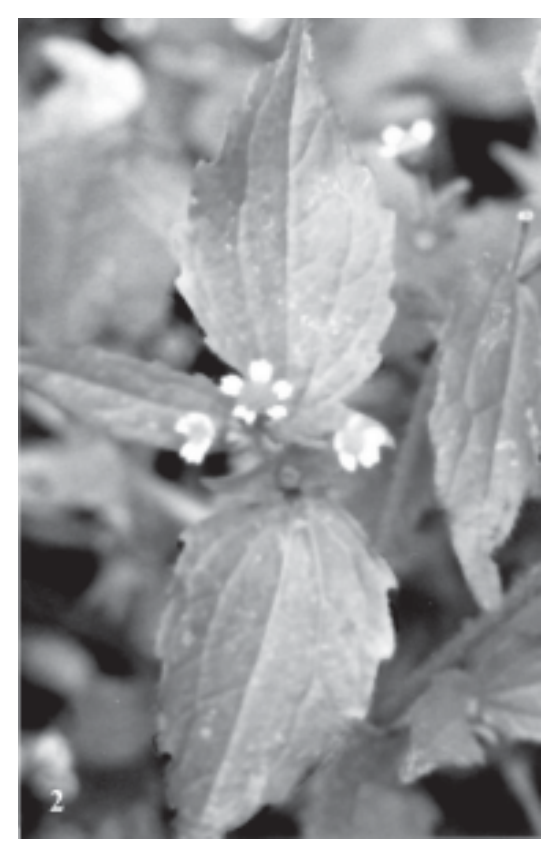

FIGURA 2 - Galinsoga ciliata (RAF.) Blake, Asteraceae:

Detalhe do Ramo com Inflorescência

Estudos fitoquímicos e farmacológicos (SENDRA, 1960; PLEKHANOVA, BANDYOKOVA, MIKHAILOVA, 1977; SZEPCZYNSKA, WOLBIS, 1984; ALICE et al., 1991; MATU, STADEN, 2003) têm procurado identificar compostos que possam fundamentar a utilização terapêutica dessas plantas medicinais, sendo que o presente trabalho objetivou acrescentar informações à identificação morfológica das mesmas, por meio da análise fotônica e ultra-estrutural da epiderme foliar.

\section{MATERIAL E MÉTODOS}

Folhas adultas foram coletadas de exemplares do Campus Jardim Botânico, do Setor de Ciências da Saúde, da Universidade Federal do Paraná, com coordenadas aproximadas de $25^{\circ} 26^{\prime}$ latitude $S$ e $49^{\circ}$ 14' longitude W. O material foi fixado em FAA50 (JOHANSEN, 1940) e foram obtidas secções transversais e paradérmicas à mão livre. Os cortes foram corados com fucsina básica e azul de astra (ROESER, 1962). A documentação foi realizada por meio de fotografias obtidas no microscópio fotônico Olympus BX40 acoplado à unidade de controle PM 20.

Para análise ultra-estrutural de superfície (microscopia eletrônica de varredura - MEV) (SOUZA, 1998), o material fixado em FAA 50 foi desidratado em etanol absoluto e pelo ponto ponto crítico de $\mathrm{CO}^{2}$ no equipamento Balzers CPD-010, e metalizado no equipamento Balzers SCD-030. A observação foi efetuada no microscópio eletrônico de varredura Philips SEM 505.

\section{RESULTADOS E DISCUSSÃO}

Galinsoga parviflora Cav. e G. ciliata (Raf.) Blake apresentam epiderme foliar uniestratificada (Fig. 3) e revestida por cutícula delgada e levemente estriada (Fig. 4). Na opinião de METCALFE e CHALK (1988), a ornamentação cuticular pode ser considerada como 
um importante caráter taxonômico e, embora ESAU (1977) e JUNIPER e JEFFREE (1983) afirmem que a deposição de ceras é comum na superfície vegetal, não se observa cera epicuticular nas espécies analisadas.

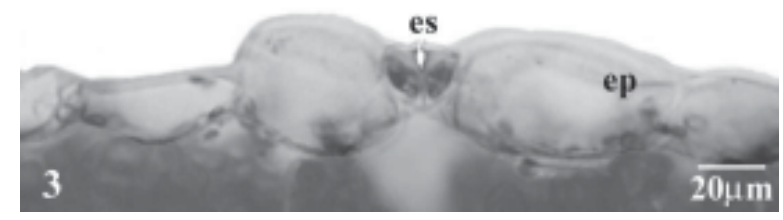

FIGURA 3 - G. ciliata: secção transversal da lâmina foliar, mostrando epiderme uniestratificada (EP) e estômato (ES) localizado no mesmo nível das demais células epidérmicas

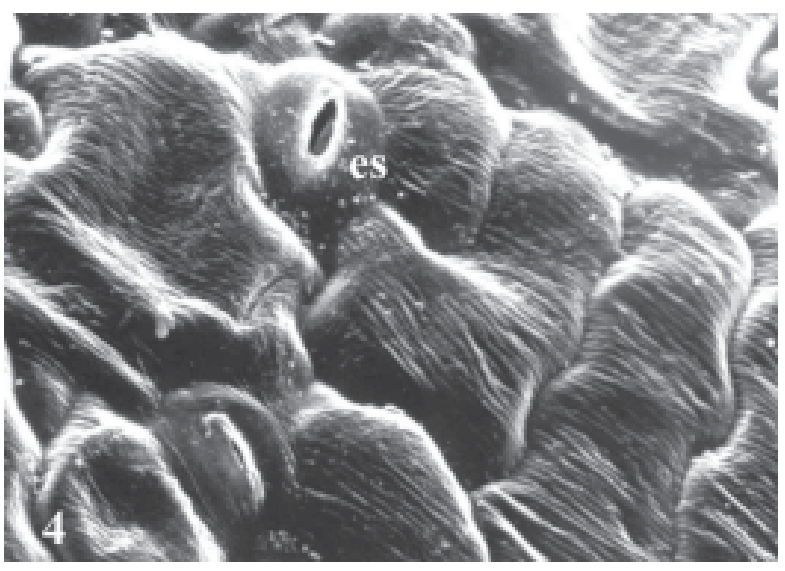

FIGURA 4 - G. ciliata: vista frontal da epiderme da lâmina foliar, revelando cutícula estriada e estômato (ES) - mev 1080x

Em vista frontal, de ambas as faces epidérmicas, as células possuem paredes anticlinais sinuosas (Fig. 5, 6), comparativamente mais evidentes na superfície abaxial. Na região das nervuras, as células assumem formato poligonal.

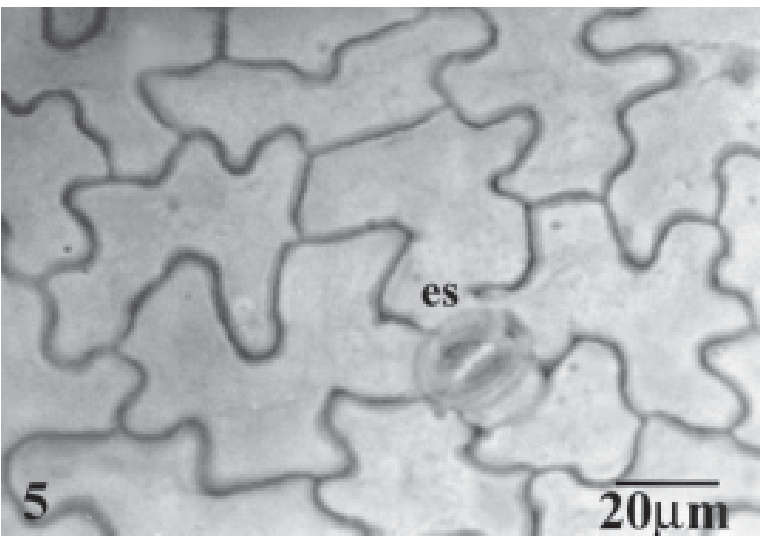

FIGURA 5 - G. parviflora: vista frontal da face adaxial da lâmina foliar, onde se nota estômato anomocítico (ES)

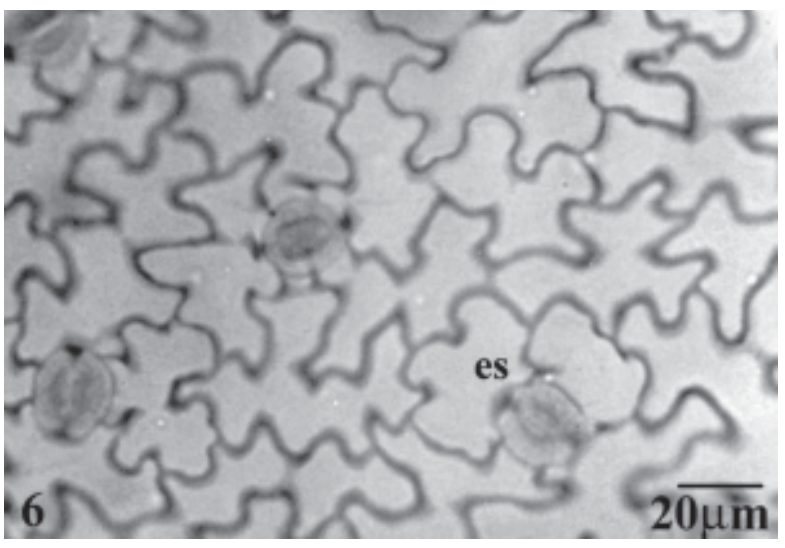

FIGURA 6 - G. parviflora: vista frontal da face abaxial da lâmina foliar, indicando estômatos anomocíticos (ES)

Tricomas tectores pluricelulares e unisseriados (Fig. 7, 8), formados por 3 a 7 células e circundados na base por 2 a 8 células menos sinuosas que as adjacentes, estão presentes com maior freqüência na superfície adaxial. 


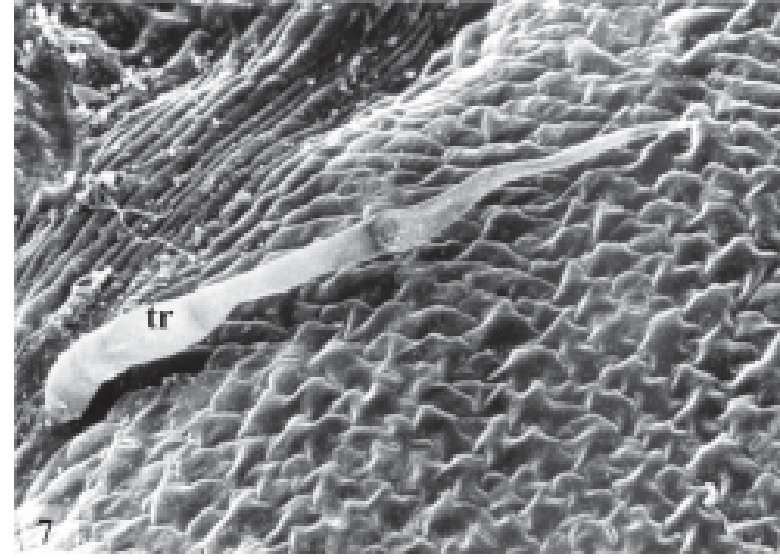

FIGURA 7 - G. parviflora: vista frontal da face adaxial da epiderme foliar, onde se observa tricoma tector pluricelular (TR) - MEV $280 x$

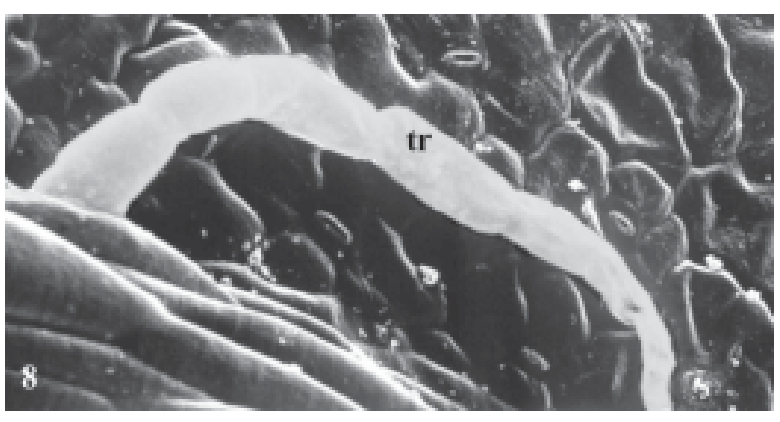

FIGURA 8 - G. ciliata: detalhe do tricoma tector pluricelular (TR) - MEV 500x

Essa ocorrência foi constatada por SENDRA (1960) em G. parviflora var. genuina. No presente estudo, G. ciliata apresenta-se com número mais elevado de tricomas em relação a G. parviflora, em concordância com DUARTE e ESTELITA (2000) para as mesmas espécies. Esses anexos epidérmicos, podem desempenhar várias funções, tais como dificultar o movimento das correntes de ar na superfície vegetal, diminuindo a perda de água (MAUSETH, 1988), bem como desempenhar papel de defesa, oferecendo uma barreira mecânica à ovoposição, à nutrição de larvas e insetos e à predação por herbívoros (CUTTER, 1986; METCALFE, CHALK, 1988).

A folha possui estômatos do tipo anomocítico (Fig. 5, 6), cujas células-guarda são ladeadas por 3 ou mais células epidérmicas semelhantes às demais e posicionadas no mesmo nível destas (Fig. 3). Ocorrem em ambas as faces, caracterizando a folha como anfiestomática, embora predominem na abaxial. Em secção transversal, revelam cristas cuticulares que se elevam e se projetam por sobre o poro estomático.

De acordo com MOTT et al. (1982), folhas anfiestomáticas têm potencialmente maior capacidade de captar monóxido de carbono e atingir níveis elevados de fotossíntese, em condições adequadas. A distribuição diferencial dos estômatos nas faces da folha é comum quando a lâmina é achatada (METCALFE, CHALK, 1988). Segundo MAUSETH (1988), o fato dos raios solares incidirem predominantemente na face adaxial, tornando-a mais sujeita à transpiração, é compensado pelo número menor de estômatos, que diminui a possível perda de vapor d'água. Em conformidade ao observado, METCALFE e CHALK (1950) registram estômatos geralmente anomocíticos (ranunculáceos) para a família Asteraceae.

\section{REFERÊNCIAS}

ALICE, C. B.; SIQUEIRA, N. C. S.; MENTZ, L. A.; SILVA, G. A. A. B.; JOSÉ, K. F. D. Plantas medicinais de uso popular: atlas farmacognóstico. Canoas: ULBRA, 1995. 205p.

ALICE, C. B.; VARGAS, V. M. F.; SILVA, G. A. A. B; SIQUEIRA, N. C. S.; SCHAPOVAL, E. E. S.; GLEYE, J.; HENRIQUES, J. A. P.; HENRIQUES, A. T. Screening of plants used in South Brazilian folk medicine. Journal of Ethnopharmacology, Limerick, v. 35, p. 165-71, 1991.

BRANDÃO, M.; BARCELAR, M.; LACA-BUENDIA, J. P.; GAVILANES, M. L.; MACEDO, J. P. Plantas daninhas existentes no herbário da empresa de pesquisa agropecuária de Minas Gerais. PAMG/EPAMIG. Daphne, Belo Horizonte, v. 1, n. 2, p. 27-43, 1991. 
CUTTER, E. G. Anatomia vegetal. Parte I - células e tecidos. 2.ed. São Paulo: Roca., 1986. 304p.

DUARTE, M. R.; ESTELITA, M. E. M. Caracteres anatômicos de folha de Galinsoga parviflora Cav. e Galinsoga ciliata (Raf.) Blake, Asteraceae. Revista Brasileira de Farmácia, Rio de Janeiro, v. 81, n. 1/2, p. 17-20, 2000.

ESAU, K. Anatomy of seed plants. $2^{\text {nd }}$ ed. New York: John Wiley, 1977. 550p.

JHA, P. K.; SAH, J. P.; CHETTRI, M. K. Amaranth productivity under biological stresses. Crop Research, Hissar, v. 5, n. 2 , p. 195-8, 1992.

JOHANSEN, D. A. Plant microtechnique. New York: McGraw Hill Book, 1940. 523p.

JUNIPER, B. E.; JEFFREE, C. E. Plant surfaces. London: Edward Arnold, 1983. 93p.

LORENZI, H.; MATOS, F. J. A. Plantas medicinais no Brasil: nativas e exóticas. Nova Odessa: Plantarum, 2002. p. 162. MACEDO, J. F.; BRANDÃO, M.; LACA-BUENDIA, J. P.; GAVILANES, M. L. Nomes populares de plantas consideradas daninhas no Estado de Minas Gerais. Daphne, Belo Horizonte, v. 1, n. 4, p. 24-31, 1991.

MATU, E. N.; STADEN, J. Antibacterial and anti-inflammatory activities of some plants used for medicinal purposes in Kenya. Journal of Ethnopharmacology, Limerick, v. 87, n. 1, p. 35-41, 2003.

MAUSETH, J. D. Plant anatomy. Menlo Park: Benjamin Cummings, 1988. 560p.

METCALFE, C. R.; CHALK, L. Anatomy of dicotyledons: leaves, stem, and wood in relation to taxonomy with notes on economic uses. Oxford: Clarendon Press, 1950. v. 2, p. 782-805.

METCALFE, C. R.; CHALK, L. Anatomy of the dicotyledons: systematic anatomy of the leaf and stem. $2^{\text {nd }}$ ed. Oxford: Clarendon Press, 1988. v. 1. 276p.

MOIT, K. A.; GIBSON, A. C.; O'LEARY, J. W. The adaptive significance of amphistomatic leaves. Plant Cell Environment, Oxford, v. 5, n. 6, p. 455-60, 1982.

PLEKHANOVA, T. I.; BANDYOKOVA, V. A.; MIKHAILOVA, G. A. Flavonoids of Galinsoga parviflora. Khimyia i Primenenie Soedinenii, Uzbekistan, n. 6, p. 862, 1977.

ROESER, K. R. Die Nadel der Schwarzkiefer-Massenprodukt und Kunstwerk der Natur. Mikrokosmos, Stuttgart, v. 61 , n. 2, p. 33-6, 1962.

SENDRA, J. Galinsoga parviflora Cav. var. genuina zóltlica drobnokwiatowa. Opracowanie farmakognostyczne. Dissertationes Pharmaceuticae, Warsaw, v. 12, n. 2, p. 121-35, 1960.

SOUZA, W. (Ed.) Técnicas básicas de microscopia eletrônica aplicadas às Ciências Biológicas. Rio de Janeiro: Sociedade Brasileira de Microscopia Eletrônica, 1998. p. 1-44.

SZEPCZYNSKA, K.; WOLBIS, M. Polyphenolic compounds of Galinsoga ciliata (Raf.) Blake (Compositae). Acta Poloniae Pharmaceutica, Warsaw, v. 41, n. 1, p. 117-21, 1984.

VIDAL, W. N.; VIDAL, M. R. R. Plantas ruderais de Viçosa. I - Compositae. Experientiae, Viçosa, v. 5, n. 2, p. 1-25, 1965.

WARWICK, S. I.; SWEET, R. D. The biology of Canadian weeds. 58. Galinsoga parviflora and G. quadriradiata (= G. ciliata). Canadian Journal of Plant Sciences, Ottawa, v. 63, n. 3, p. 695-710, 1983.

WEHMEYER, A. S.; ROSE, E. F. Important indigenous plants used in the Transkei as food supplements. Bothalia, Pretoria, v. 14, n. 3/4, p. 613-5, 1983. 